\title{
Effects of Single Pill Combinations Compared to Identical Multi Pill Therapy on Outcomes in Hypertension, Dyslipidemia and Secondary Cardiovascular Prevention: The START-Study
}

\author{
Thomas Wilke', Burkhard Weisser ${ }^{2}$, Hans-Georg Predel ${ }^{3}$, Roland Schmieder ${ }^{4}$, Sven Wassmann ${ }^{5}$, \\ Anton Gillessen ${ }^{6}$, Jörg Blettenberg ${ }^{7}$, Ulf Maywald ${ }^{8}$, Olaf Randerath ${ }^{9}$, Sabrina Mueller $\mathbb{D}^{10}$, \\ Michael Böhm"I \\ 'Institut für Pharmakoökonomie und Arzneimittellogistik (IPAM)/Institute for Pharmacoeconomics and Pharmaceutical Logistics, Wismar, Germany; \\ ${ }^{2}$ Institute of Sports Science, Christian-Albrechts-University of Kiel, Kiel, Germany; ${ }^{3}$ Institute of Cardiology and Sports Medicine, German Sport University, \\ Cologne, Germany; ${ }^{4}$ Department of Nephrology and Hypertension, University Hospital Erlangen, Friedrich Alexander University Erlangen Nürnberg, \\ Erlangen, Germany; ${ }^{5}$ Faculty of Medicine, Cardiology Pasing, Munich and University of the Saarland, Homburg/Saar, Germany; ${ }^{6}$ Department of Internal \\ Medicine, Herz-Jesu-Hospital, Münster, Germany; ${ }^{7}$ Practice Dr. J. Blettenberg, Lindlar, Germany; ${ }^{8}$ AOK PLUS - The Health Insurance for Sachsen und \\ Thüringen; GB Medicines/Remedies, Dresden, Germany; ${ }^{9}$ Medical Department, APONTIS PHARMA GmbH \& Co.KG, Monheim, Germany; ${ }^{10}$ Ingress-Health \\ HWM GmbH, Wismar, Germany; " Clinic for Internal Medicine III, University Clinic of Saarland, Saarland University, Homburg/Saar, Germany
}

Correspondence: Thomas Wilke, Institute of Pharmacoeconomics and Medication Logistics, University of Wismar, Alter Holzhafen 19, Wismar, 23966, Germany, Tel +49384I758I0I4, Fax +49384I758I0II, Email Thomas.wilke@ipam-wismar.de

Aim: Current guidelines for the treatment of arterial hypertension $(\mathrm{AH})$ or cardiovascular $(\mathrm{CV})$ prevention recommend combination drug treatments with single pill combinations (SPC) to improve adherence to treatment. We aimed to assess whether the SPC concept is clinically superior to multi pill combination (MPC) with identical drugs.

Methods and Results: In an explorative study, we analyzed anonymized claims data sets of patients treated with CV drugs for hypertension and/or CV disorders who were insured by the German AOK PLUS statutory health fund covering 01/07/2012-30/06/2018. Patients at age $\geq 18$ years who received either a SPC or MPC with identical drugs were followed for up to one year. A one to one propensity score matching (PSM) was applied within patient groups who started identical drug combinations, and results were reported as incidence rate ratios (IRRs) as well as hazard ratios (HRs). After PSM, data from 59,336 patients were analyzed. In 30 out of 56 IRR analyses, superiority of SPC over MPC was shown. In 5 out of 7 comparisons, the HR for the composite outcome of all-cause death and all-cause hospitalizations was in favor of the SPC regimen (SPC versus MPC): valsartan/amlodipine: HR=0.87 (95\% CI: 0.84-0.91, p $\leq 0.001)$; candesartan/amlodipine: 0.77 (95\% CI: $0.65-$ $0.90, \mathrm{p}=0.001)$; valsartan/amlodipine/hydrochlorothiazide: $\mathrm{HR}=0.68$ (95\% CI: $0.61-0.74, \mathrm{p} \leq 0.001)$; ramipril/amlodipine: $\mathrm{HR}=0.80$ (95\% CI: $0.77-0.83, \mathrm{p} \leq 0.001)$; acetylsalicylic acid (ASA)/atorvastatin/ramipril: $\mathrm{HR}=0.64$ (95\% CI: $0.47-0.88, \mathrm{p}=0.005)$.

Conclusion: SPC regimens are associated with a lower incidence of CV events and lower all-cause mortality in clinical practice. SPC regimens should generally be preferred to improve patient's prognosis.

Keywords: single pill, adherence, cardiovascular outcomes, mortality, prognosis, clinical practice

\section{Introduction}

In 2015, about 49 million people across Europe suffered from at least one cardiovascular disease (CVD) including a high prevalence of hypertension and hyperlipidemia. ${ }^{1}$ Antihypertensives and lipid-lowering agents are the medical cornerstones of prevention $^{2}$ with most patients require multi-drug treatments. ${ }^{3}$ It is known that adherence to medication decreases with any additional pill, ${ }^{4}$ and non-adherence is common in clinical practice. ${ }^{5-8}$ As non-adherence is associated with poor control of blood pressure and cholesterol, which might be associated with adverse CV outcomes, ${ }^{9}$ single pill combinations (SPC) are now recommended by national and international contemporary guidelines. ${ }^{3}$ 
In currently existing SPC, up to three different agents can be combined to one pill, reducing the pill burden in comparison to multi pill combination (MPC). A large body of literature showed that adherence with many chronic CV medications is poor, ${ }^{9-12}$ and it could be demonstrated that SPC are associated with improved adherence and better blood pressure control. ${ }^{6,13-16}$ Our observational longitudinal study aimed to add to this evidence by analyzing whether SPC are superior to the identical MPC relating to cardiovascular (CV) outcomes and mortality in a real-world setting. We analyzed data from patients with hypertension, and/or CV disease such has heart failure (HF), coronary heart disease (CHD) and stroke. We mainly focused on combinations recommended for the treatment of hypertension.

\section{Methods}

\section{Study Design}

In this analysis, we assessed clinical outcomes for patients aged 18 years or older suffering from CV disorders and treated with a combination as SPC or identical MPC. We used anonymized claims data sets from AOK PLUS, a German statutory health fund, with 3.2 million insured persons that covered the period 01/07/2012-30/06/2018. The data set provided information on socio-demographic characteristics of patients, inpatient and outpatient care as well as all documented diagnoses, prescriptions of medications, and other data such as prescriptions of outpatient aids and devices.

\section{Patients}

Patients aged 18 years or older were included in the analysis if they were continuously insured (07/2012-06/2018, death as only exception from this rule) and had at least one inpatient or two outpatient claims (in two different quarters) of at least one of the following diseases in 01/07/2012-30/06/2017: hypertension, CHD, hyperlipidemia, myocardial infarction (MI), HF, stroke, transient ischemic attack (TIA), CHD or peripheral artery disease. The International Code of Diseases (ICD) was chosen for disease classification because validity of recording and coding is high in statutory health fund data, especially for inpatient and prescription data, as they are directly relevant for reimbursement of hospitals/pharmacies, and regularly checked by external agencies.

Based on above patients, we subsequently selected different sub-cohorts according to specific drug treatment profile. The following agent combinations, either as SPC or identical MPC were selected: bisoprolol/amlodipine (BIS/AMLO), valsartan/amlodipine (VAL/AMLO), candesartan/amlodipine (CAR/AMLO), valsartan/amlodipine/hydrochlorothiazide (VAL/AMLO/HCTZ), ramipril/amlodipine (RAMI/AMLO), ezetimibe/atorvastatin (EZE/ATOR), acetylsalicylic acid / atorvastatin/ramipril (ASA/ATOR/RAMI).

Furthermore, at least a diagnosis of hypertension (BIS/AMLO, VAL/AMLO, CAR/AMLO, VAL/AMLO/HCTZ, RAMI/ AMLO) and at least one event as MI or HF or TIA or stroke or embolism or peripheral artery disease (ASA/ATOR/RAMI) or dyslipidemia (EZE/ATOR) were required for patient inclusion in above mentioned sub-cohorts confirmed by ICD. Multiple assignments of patients to groups were possible. Analysis of one additional cohort was planned (atorvastatin/perindopril/ amlodipine) but could not be done due to low sample sizes (105 SPC and 6 MPC patients).

\section{Observational Period}

Patients were included who started their combination therapy between 01/07/2013 and 30/06/2017. Prescription of a respective combination therapy in 2012 led to exclusion of a patient (Figure 1). Observation of patients started at the date of the first prescription of combination therapy (index date), either as SPC or MPC. Index date for the SPC group was the first prescription of a respective SPC. A MPC was assumed to have been prescribed if there were claims of all agents of the targeted combination therapy within 90 days; index date was the prescription date of the last (second/third) agent in that combination.

\section{Propensity Score Matching}

To account for baseline differences, a propensity score matching (PSM) was done in each of the subgroups. In the PSM analysis, patients in the SPC cohort were, per subgroup, separately matched to patients in the MPC cohort. Propensity scores were calculated using logistic regression (group affiliation as dependent variable) including age, gender, and Charlson Comorbidity Index (CCI) without age factor as fixed independent variables. All were based on information 


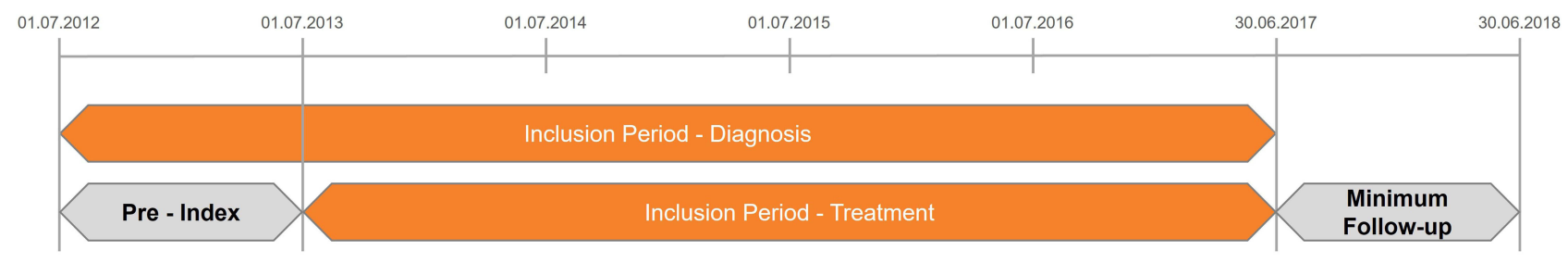

Figure I Baseline, inclusion and observational periods of the study.

related to index date or a 12 months baseline period. Furthermore, 29 different variables that are plausible as predictors of $\mathrm{CV}$ outcomes available in the database describing the CV event risk or the general comorbidity profile of above patients, were included as independent variables (Supplemental Table 1).

A backward elimination approach was used to eliminate any variables that did not reach significance in explaining group exposition $(\mathrm{p}>0.1)$; in such cases these variables were excluded from the specific PSM models. Each PSM was done using a one to one matching approach and the maximum accepted difference in propensity scores was 0.001 . PSM quality was assessed in two ways: 1) assessment of standardized differences between comparison groups were used to assess the balance of covariates after matching (number of variables with significant differences between SPC and MPC patients); and 2) assessment of incidence of a specific event that was expected to be independent of the drug treatment received (knee/hip replacement surgery) in the follow-up period.

\section{Follow-Up Periods and Study Outcomes}

Patients were followed up from index date until one of the following events, whatever came first: End of data availability (30/06/2018), all-cause death, therapy discontinuation, in line with previous literature, defined as gap in drug supply of at least 60 days, ${ }^{17,18}$ based on the defined daily dose (DDD) per agent, in case of a MPC a gap of 60 days for at least one of the combination agents led to censoring in that respect, switch from SPC to MPC or vice versa.

The following eight acute and non-planned clinical outcomes reported as main diagnoses were captured: hospitalizations with MI, acute hospitalizations for stroke or TIA, hospitalizations for CHD and hospitalizations for HF. The outcomes of all-cause death, all-cause hospitalizations within 2 weeks before death and all-cause hospitalizations as well as the composite were also captured following the ICD paradigm.

\section{Statistical Analysis}

Based on a patient-specific follow-up period since index date, the following numbers were separately reported for all outcome categories: First, we counted the number of events per observed 100 patient years and, based on this, calculated incidence rate ratios (IRRs) for the exposure of a patient to the SPC versus MPC cohorts. Second, we calculated unadjusted hazard ratios (HRs) based on unadjusted Cox regression models. Third, the percentage of event-free patients over time with regard to the outcomes of interest as well as with regard to a composite outcome consisting of all-cause hospitalizations was depicted in Kaplan-Meier (KM) curves using log rank tests for testing statistical significance of differences between the observed cohorts.

To address the issue of confounding, two additional analyses were conducted: an analysis of number of events in a Poisson regression and a multivariable Cox regression analysis both based on the unmatched SPC/MPC samples within above cohorts. Results were reported as coefficients for SPC vs. MPC (Poisson regression) and adjusted HRs (aHRs, Cox regression). All variables included in the PSM procedure were included in these models as independent variables using a backward elimination approach.

All reported p-values were two-sided, and 95\% CIs were calculated for IRRs, HRs, Poisson-coefficients and aHRs by applying independent t-tests or Wilcoxon Rank Sum tests, where applicable. For categorical variables, the Chi Squared 
Test was performed. All descriptive analyses were performed with Microsoft SQL Server 2014 and Microsoft Excel 2016. All other statistical analyses were performed with STATA/MP 13.1 and SPSS 17.0.

\section{Regulatory Aspects}

Because the study was non-interventional, had a retrospective design, and was based on anonymized data, informed consent of patients and ethical approval were not required. This is in accordance with German law and policies of the institutions assessing patient-level data (IPAM and AOK PLUS). The study was evaluated by a scientific steering committee to which all the authors belonged and was based on a study protocol approved before start of data analysis. The scientific steering committee was formed by the authors of the manuscript, that included representatives from the data provider to align in advance on design and execution aspects of the study.

\section{Results}

We identified a total of 1,369,840 continuously insured patients with at least one of the target diagnoses (Figure 2). Of these, the patient numbers for matched and unmatched cohorts are given in Table 1 and Figure 2.

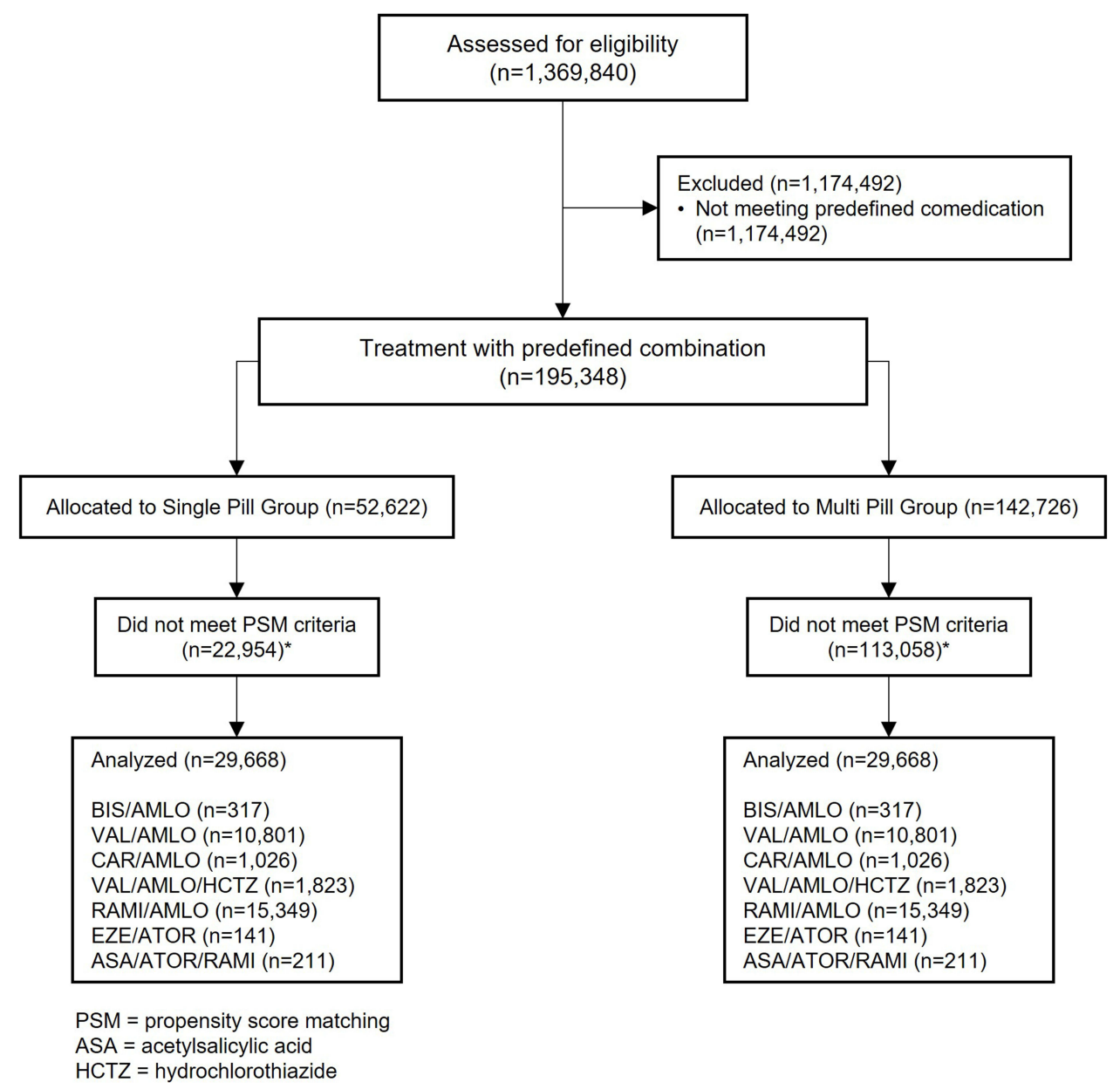

Figure 2 Consort flow diagram. 
Table I Number of Patients in Unmatched and Matched Cohorts

\begin{tabular}{|c|c|c|c|}
\hline & $\begin{array}{l}\text { Number of Patients } \\
\text { on SPC Before PSM }\end{array}$ & $\begin{array}{l}\text { Number of Patients on } \\
\text { MPC Before PSM }\end{array}$ & $\begin{array}{l}\text { Number of Patients in } \\
\text { Each Group After PSM }\end{array}$ \\
\hline Total Number of Patients* & 52,517 & 142,720 & 29,668 \\
\hline \multicolumn{4}{|l|}{ Combination } \\
\hline Bisoprolol/amlodipine & 338 & 37,172 & 317 \\
\hline Valsartan/amlodipine & 12,296 & 25,424 & $10,80 \mid$ \\
\hline Candesartan/amlodipine & 2,256 & 15,756 & 1,026 \\
\hline Valsartan/amlodipine/hydrochlorothiazide & 17,682 & 4,419 & 1,823 \\
\hline Ramipril/amlodipine & 16,806 & 52,288 & 15,349 \\
\hline Ezetimibe/atorvastatin & 2,864 & 999 & $14 \mid$ \\
\hline ASA/atorvastatin/ramipril & 275 & 6,662 & 211 \\
\hline
\end{tabular}

Notes: *III patients that could not be matched due to low sample sizes are not shown (I05 SPC and 6 MPC patients).

Abbreviations: SPC, single pill combination; MPC, multi pill combination, PSM, propensity score matching.

After the defined PSM procedures, patient characteristics were similar between compared patients. Mean age, percentage of female patients and mean CCI in the seven cohorts are given in Table 2. In terms of PSM quality, we could not detect any significant differences in number of hip/knee replacement surgeries between compared cohorts, with the exception of VAL/AMLO (Table 2).

The mean follow-up period since index date in the SPC/MPC cohorts are also given in Table 2. Percentage of patients still continuing the index therapy after 12 months was as follows (SPC/MPC) in the seven PSM cohorts: BIS/AMLO: 75.7\% vs. 20.8\% (p $\leq .001$ ); VAL/AMLO: $69.4 \%$ vs. $49.2 \%$ (p $\leq 0.001)$; CAR/AMLO: $71.1 \%$ vs. $40.6 \%$ (p $\leq 0.001)$; VAL/AMLO/HCTZ: $75.4 \%$ vs. $25.9 \%$ (p $\leq 0.001$ ); RAMI/AMLO: $76.1 \%$ vs. $52.5 \%$ (p $\leq 0.001$ ).; EZE/ATOR: $69.5 \%$ vs. $47.5 \%$ (p $\leq 0.001)$; ASA/ATOR/RAMI: $80.6 \%$ vs. $28.0 \%$ ( $\leq 0.001)$.

\section{Event Risk Comparisons Between SPC/MPC Patients}

In 30 out of the 56 IRR analyses, based on the PSM cohorts, a significant superiority of a SPC over MPC could be demonstrated in Table 3. The SPC was associated: 1) with a lower risk for CHD in the combinations VAL/AMLO, CAR/ AMLO, VAL/AMLO/HCTZ, and EZE/ATOR; 2) a lower risk for HF in VAL/AMLO, CAR/AMLO, and VAL/AMLO/ HCTZ; 3) a lower risk for stroke in VAL/AMLO, VAL/AMLO/HCTZ; 4) a lower risk for TIA for VAL/AMLO and VAL/ AMLO/HCTZ; and 5) a lower risk for all-cause mortality in VAL/AMLO, CAR/AMLO, and VAL/AMLO/HCTZ. In RAMI/AMLO a SPC was associated with lower event risk in all observed outcomes including MI.

The IRR for all-cause hospitalization was significantly in favor in all SPC except EZE/ATOR, which also showed a tendency for less hospitalizations under SPC (Figure 3).

For the pre-defined composite outcome consisting of all-cause death and all-cause hospitalizations, in five out of seven of the comparisons, the HR was in favor of the SPC regimen. The generalized linear model (Poisson regression) as well as the multivariable Cox regression based on the unmatched cohorts generally confirmed the above analysis results. Except BIS/AMLO and EZE/ATOR, all SPC are significant superior over MPC (Figure 4).

\section{Discussion}

Current guidelines for the management of hypertension and CV disease protection recommend drug combination treatments to reduce $\mathrm{CV}$ events and mortality. ${ }^{2}$ The evidence for recommended combinations is based on randomized controlled trials (RCTs) that are conducted in a highly controlled environment in which adherence to the prescribed 
Table 2 Patient Characteristics After PSM

\begin{tabular}{|c|c|c|c|c|c|c|c|c|c|}
\hline & $\begin{array}{l}\text { Mean Age in } \\
\text { Years SPCI } \\
\text { MPC } \\
\text { (p-value) }\end{array}$ & $\begin{array}{l}\text { \% Female } \\
\text { Patients } \\
\text { SPC/MPC } \\
\text { (p-value) }\end{array}$ & $\begin{array}{l}\text { Mean } \\
\text { CCI } \\
\text { SPCI } \\
\text { MPC } \\
\text { (p-value) }\end{array}$ & $\begin{array}{l}\text { Mean CHA } \\
\text { DS }_{2} \text {-VASc- } \\
\text { Score } \\
\text { SPC/MPC } \\
\text { (p-value) }\end{array}$ & $\begin{array}{l}\text { Mean Number } \\
\text { of Prescribed } \\
\text { Agents } \\
\text { SPC/MPC } \\
\text { (p-value) }\end{array}$ & $\begin{array}{l}\text { Mean nb. of CV } \\
\text { Hospitalizations } \\
\text { SPC/MPC } \\
\text { (p-value) }\end{array}$ & $\begin{array}{l}\text { Mean Number } \\
\text { of Any } \\
\text { Hospitalizations } \\
\text { SPC/MPC } \\
\text { (p-value) }\end{array}$ & $\begin{array}{l}\text { Mean Number of } \\
\text { Knee-/Hip- } \\
\text { Replacements } \\
\text { SPC/MPC } \\
\text { (p-value) }\end{array}$ & $\begin{array}{l}\text { Mean } \\
\text { Observational } \\
\text { Period in Days } \\
\text { SPC/MPC } \\
\text { (p-value) }\end{array}$ \\
\hline $\begin{array}{l}\text { BIS/AMLO } \\
n=317 / 317\end{array}$ & $\begin{array}{c}64.91 / 64.76 \\
(p=0.896)\end{array}$ & $\begin{array}{c}55.21 \% / 57.14 \% \\
\quad(p=0.631)\end{array}$ & $\begin{array}{l}2.12 / 1.99 \\
(p=0.485)\end{array}$ & $\begin{array}{l}3.03 / 3.11 \\
(p=0.531)\end{array}$ & $\begin{array}{l}4.26 / 4.02 \\
(p=0.379)\end{array}$ & $\begin{array}{l}0.02 / 0.02 \\
(p=0.794)\end{array}$ & $\begin{array}{l}0.32 / 0.36 \\
(p=0.562)\end{array}$ & $0.01 / 0.01 \quad(p=1.000)$ & $\begin{array}{c}352.46 / 272.88 \\
(p=0.00 I)\end{array}$ \\
\hline $\begin{array}{l}\text { VAL/AMLO } \\
n=|0,80| /|0,80|\end{array}$ & $\begin{array}{c}69.74 / 69.62 \\
(p=0.49 I)\end{array}$ & $\begin{array}{c}57.12 \% / 56.70 \% \\
\quad(p=0.640)\end{array}$ & $\begin{array}{l}3.28 / 3.29 \\
(p=0.873)\end{array}$ & $\begin{array}{l}3.66 / 3.65 \\
(p=0.74 I)\end{array}$ & $\begin{array}{l}5.85 / 5.86 \\
(p=0.798)\end{array}$ & $\begin{array}{l}0.12 / 0.12 \\
(p=0.882)\end{array}$ & $\begin{array}{l}0.89 / 0.92 \\
(p=0.153)\end{array}$ & $0.02 / 0.01 \quad(p=0.703)$ & $\begin{array}{c}601.15 / 501.24 \\
(p<0.001)\end{array}$ \\
\hline $\begin{array}{l}\text { CAR/AMLO } \\
n=1,026 / 1,026\end{array}$ & $\begin{array}{c}66.36 / 65.47 \\
(p=0.144)\end{array}$ & $\begin{array}{c}56.02 \% / 55.12 \% \\
(p=0.657)\end{array}$ & $\begin{array}{l}2.29 / 2.25 \\
(p=0.765)\end{array}$ & $\begin{array}{l}3.09 / 3.07 \\
(p=0.833)\end{array}$ & $\begin{array}{l}4.44 / 4.47 \\
(p=0.821)\end{array}$ & $\begin{array}{l}0.05 / 0.05 \\
(p=0.948)\end{array}$ & $\begin{array}{l}0.49 / 0.49 \\
(p=0.784)\end{array}$ & $0.01 / 0.02(p=0.823)$ & $\begin{array}{c}386.12 / 427.94 \\
\quad(p=0.005)\end{array}$ \\
\hline $\begin{array}{l}\text { VAL/AMLO/HCTZ } \\
n=I, 823 / I, 823\end{array}$ & $\begin{array}{c}71.55 / 71.30 \\
(p=0.555)\end{array}$ & $\begin{array}{c}59.21 \% / 58.61 \% \\
\quad(p=0.7 \mid I)\end{array}$ & $\begin{array}{l}3.95 / 3.99 \\
(p=0.66 I)\end{array}$ & $\begin{array}{l}3.98 / 4.01 \\
(p=0.526)\end{array}$ & $\begin{array}{l}7.04 / 7.14 \\
(p=0.496)\end{array}$ & $\begin{array}{l}0.19 / 0.12 \\
(p=0.766)\end{array}$ & $\begin{array}{l}1.30 / 1.27 \\
(p=0.591)\end{array}$ & $0.02 / 0.02(p=1.000)$ & $\begin{array}{c}598.09 / 212.56 \\
(p<0.001)\end{array}$ \\
\hline $\begin{array}{l}\text { RAMI/AMLO } \\
n=15,349 / 15,349\end{array}$ & $\begin{array}{c}64.88 / 64.72 \\
(p=0.307)\end{array}$ & $\begin{array}{c}48.24 \% / 48.42 \% \\
\quad(p=0.740)\end{array}$ & $\begin{array}{l}2.04 / 2.02 \\
(p=0.443)\end{array}$ & $\begin{array}{l}2.92 / 2.93 \\
(p=0.338)\end{array}$ & $\begin{array}{l}4.06 / 4.01 \\
(p=0.166)\end{array}$ & $\begin{array}{l}0.04 / 0.04 \\
(p=0.062)\end{array}$ & $\begin{array}{l}0.4 \mathrm{I} / 0.43 \\
(p=0.053)\end{array}$ & $0.01 / 0.01 \quad(p=1.000)$ & $\begin{array}{c}642.39 / 505.46 \\
(p<0.001)\end{array}$ \\
\hline $\begin{array}{l}\text { EZE/ATOR } \\
n=|4| / 14 \mid\end{array}$ & $\begin{array}{c}64.81 / 64.03 \\
(p=0.569)\end{array}$ & $\begin{array}{c}31.22 \% / 32.63 \% \\
\quad(p=0.799)\end{array}$ & $\begin{array}{l}3.77 / 3.97 \\
(p=0.436)\end{array}$ & $\begin{array}{l}3.62 / 3.69 \\
(p=0.714)\end{array}$ & $\begin{array}{l}6.37 / 6.40 \\
(p=0.954)\end{array}$ & $\begin{array}{l}0.02 / 0.03 \\
(p=0.703)\end{array}$ & $\begin{array}{l}1.01 / 0.99 \\
(p=0.845)\end{array}$ & $0.01 / 0.00(p=0.393)$ & $\begin{array}{c}479.35 / 274.80 \\
(p<0.00 I)\end{array}$ \\
\hline $\begin{array}{l}\text { ASA/ATOR/RAMI } \\
n=2|l / 2| l\end{array}$ & $\begin{array}{c}68.34 / 69.21 \\
(p=0.432)\end{array}$ & $\begin{array}{c}29.45 \% / 30.31 \% \\
\quad(p=0.832)\end{array}$ & $\begin{array}{l}3.72 / 3.43 \\
(p=0.191)\end{array}$ & $\begin{array}{l}3.63 / 3.68 \\
(p=0.708)\end{array}$ & $\begin{array}{l}5.63 / 5.53 \\
(p=0.758)\end{array}$ & $\begin{array}{l}0.02 / 0.01 \\
(p=0.412)\end{array}$ & $\begin{array}{l}0.82 / 0.84 \\
(p=0.4 I 2)\end{array}$ & $0.01 / 0.01 \quad(p=1.000)$ & $\begin{array}{c}476.68 / 282.20 \\
(p<0.00 I)\end{array}$ \\
\hline
\end{tabular}

Abbreviations: BIS/AMLO, bisoprolol/amlodipine; VAL/AMLO, valsartan/amlodipine; CAR/AMLO, candesartan/amlodipine; VAL/AMLO/HCTZ, valsartan/amlodipine/hydrochlorothiazide; RAMI/AMLO, ramipril/amlodipine; EZE/ATOR, ezetimibe/atorvastatin; ASA/ATOR/RAMI, ASA/atorvastatin/ramipril; CCI, Charlson Comorbidities Index. 
Table 3 Main Results: Event Risk Comparison Between SPC and MPC Patients, Based on Matched Cohorts

\begin{tabular}{|c|c|c|c|c|c|c|c|}
\hline & $\begin{array}{l}\text { MI } \\
\text { IRR (95\%-CI) } \\
\text { p-value }\end{array}$ & $\begin{array}{l}\text { Coronary Artery } \\
\text { Disease } \\
\text { IRR }(95 \%-\mathrm{Cl}) \\
\text { p-value }\end{array}$ & $\begin{array}{l}\text { HF } \\
\text { IRR (95\%-CI) } \\
\text { p-value }\end{array}$ & $\begin{array}{l}\text { Stroke } \\
\text { IRR }(95 \%-\mathrm{CI}) \\
\text { p-value }\end{array}$ & $\begin{array}{l}\text { Transient Ischemic } \\
\text { Attack } \\
\text { IRR (95\%-CI) } \\
\text { p-value }\end{array}$ & $\begin{array}{l}\text { All Cause } \\
\text { Mortality } \\
\text { IRR (95\%-CI) } \\
\text { p-value }\end{array}$ & $\begin{array}{l}\text { CV } \\
\text { Hospitalization } \\
\text { IRR (95\%-CI) } \\
\text { p-value }\end{array}$ \\
\hline $\begin{array}{l}\text { BIS/AMLO } \\
n=317\end{array}$ & $\begin{array}{l}0.774(0.056-10.677) \\
P=0.810\end{array}$ & $\begin{array}{l}0.387(0.007-7.433) \\
P=0.488\end{array}$ & $\begin{array}{l}0.929(0.236-3.847) \\
P=0.899\end{array}$ & $\begin{array}{l}\text { I.032 (0.175-7.045) } \\
P=0.98 \mathrm{I}\end{array}$ & $\begin{array}{l}0.774(0.056-10.677) \\
P=0.810\end{array}$ & $\begin{array}{l}0.580(0.166-1.908) \\
p=0.325\end{array}$ & $\begin{array}{l}0.633(0.184-2.305) \\
p=0.473\end{array}$ \\
\hline $\begin{array}{l}\text { VAL/AMLO } \\
n=|0,80|\end{array}$ & $\begin{array}{l}0.964(0.767-\mid .2 I) \\
p=0.745\end{array}$ & $\begin{array}{l}0.768(0.62 I-0.948) \\
P=0.012\end{array}$ & $\begin{array}{l}0.683(0.623-0.750) \\
P=0.001\end{array}$ & $\begin{array}{l}0.767(0.635-0.926) \\
p=0.005\end{array}$ & $\begin{array}{l}0.698(0.500-0.970) \\
P=0.026\end{array}$ & $\begin{array}{l}0.761(0.683-0.848) \\
p \leq 0.001\end{array}$ & $\begin{array}{l}0.693(0.614-0.782) \\
p \leq 0.001\end{array}$ \\
\hline $\begin{array}{l}\text { CAR/AMLO } \\
n=1,026\end{array}$ & $\begin{array}{l}0.879(0.129-5.195) \\
P=0.883\end{array}$ & $\begin{array}{l}0.270(0.049-0.984) \\
p=0.029\end{array}$ & $\begin{array}{l}0.402(0.190-0.793) \\
P=0.004\end{array}$ & $\begin{array}{l}0.72 \mid(0.259-\mid .877) \\
p=0.478\end{array}$ & $\begin{array}{l}0.586(0.010-11.256) \\
p=0.716\end{array}$ & $\begin{array}{l}0.538(0.284-0.980) \\
P=0.031\end{array}$ & $\begin{array}{l}0.599(0.346-1.011) \\
p=0.043\end{array}$ \\
\hline $\begin{array}{l}\text { VAL/AMLO/ } \\
\text { HCTZ } \\
n=1,823\end{array}$ & $\begin{array}{l}0.739(0.395-1.428) \\
P=0.322\end{array}$ & $\begin{array}{l}0.314(0.183-0.532) \\
p \leq 0.001\end{array}$ & $\begin{array}{l}0.432(0.322-0.579) \\
p \leq 0.001\end{array}$ & $\begin{array}{l}0.538(0.338-0.862) \\
P=0.007\end{array}$ & $\begin{array}{l}0.179(0.057-0.497) \\
p \leq 0.001\end{array}$ & $\begin{array}{l}0.515(0.375-0.709) \\
p \leq 0.001\end{array}$ & $\begin{array}{l}0.450(0.328-0.620) \\
p \leq 0.001\end{array}$ \\
\hline $\begin{array}{l}\text { RAMI/AMLO } \\
n=15,349\end{array}$ & $\begin{array}{l}0.623(0.493-0.784) \\
p \leq 0.001\end{array}$ & $\begin{array}{l}0.579(0.462-0.723) \\
p \leq 0.001\end{array}$ & $\begin{array}{l}0.468(0.409-0.534) \\
p \leq 0.001\end{array}$ & $\begin{array}{l}0.746(0.627-0.886) \\
p \leq 0.001\end{array}$ & $\begin{array}{l}0.693(0.496-0.963) \\
p=0.023\end{array}$ & $\begin{array}{l}0.526(0.463-0.596) \\
p \leq 0.001\end{array}$ & $\begin{array}{l}0.596(0.519-0.685) \\
p \leq 0.001\end{array}$ \\
\hline $\begin{array}{l}\text { EZE/ATOR } \\
n=|4|\end{array}$ & $\begin{array}{l}0.870(0.147-5.938) \\
P=0.849\end{array}$ & $\begin{array}{l}0.077(0.009-0.323) \\
p \leq 0.001\end{array}$ & $\begin{array}{l}4.567(I .049-4 I .402) \\
P=0.024\end{array}$ & $\begin{array}{l}0.000(0.000-25.444) \\
P=0.395\end{array}$ & N/A & $\begin{array}{l}1.631(0.267-17.128) \\
p=0.597\end{array}$ & $\begin{array}{l}0.870(0.147-5.938) \\
p=0.849\end{array}$ \\
\hline $\begin{array}{l}\text { ASA/ATOR/RAMI } \\
n=21 I\end{array}$ & $\begin{array}{l}0.459(0.07 I-2.362) \\
p=0.304\end{array}$ & $\begin{array}{l}0.602(0.247-1.427) \\
P=0.213\end{array}$ & $\begin{array}{l}1.340(0.525-3.687) \\
p=0.521\end{array}$ & $\begin{array}{l}0.5 I I(0.043-4.457) \\
P=0.493\end{array}$ & $\begin{array}{l}0.766(0.010-60.115) \\
p=0.867\end{array}$ & $\begin{array}{l}0.383(0.062-1.793) \\
p=0.182\end{array}$ & $\begin{array}{l}0.5 I I(0.150-1.606) \\
p=0.209\end{array}$ \\
\hline
\end{tabular}

Abbreviations: BIS/AMLO, bisoprolol/amlodipine; VAL/AMLO, valsartan/amlodipine; CAR/AMLO, candesartan/amlodipine; VAL/AMLO/HCTZ, valsartan/amlodipine/hydrochlorothiazide; RAMI/AMLO, ramipril/amlodipine; EZE/ATOR, ezetimibe/atorvastatin; ASA/ATOR/RAMI, ASA/atorvastatin/ramipril; IRR, incidence rate ratios; Cl, confidence interval. 


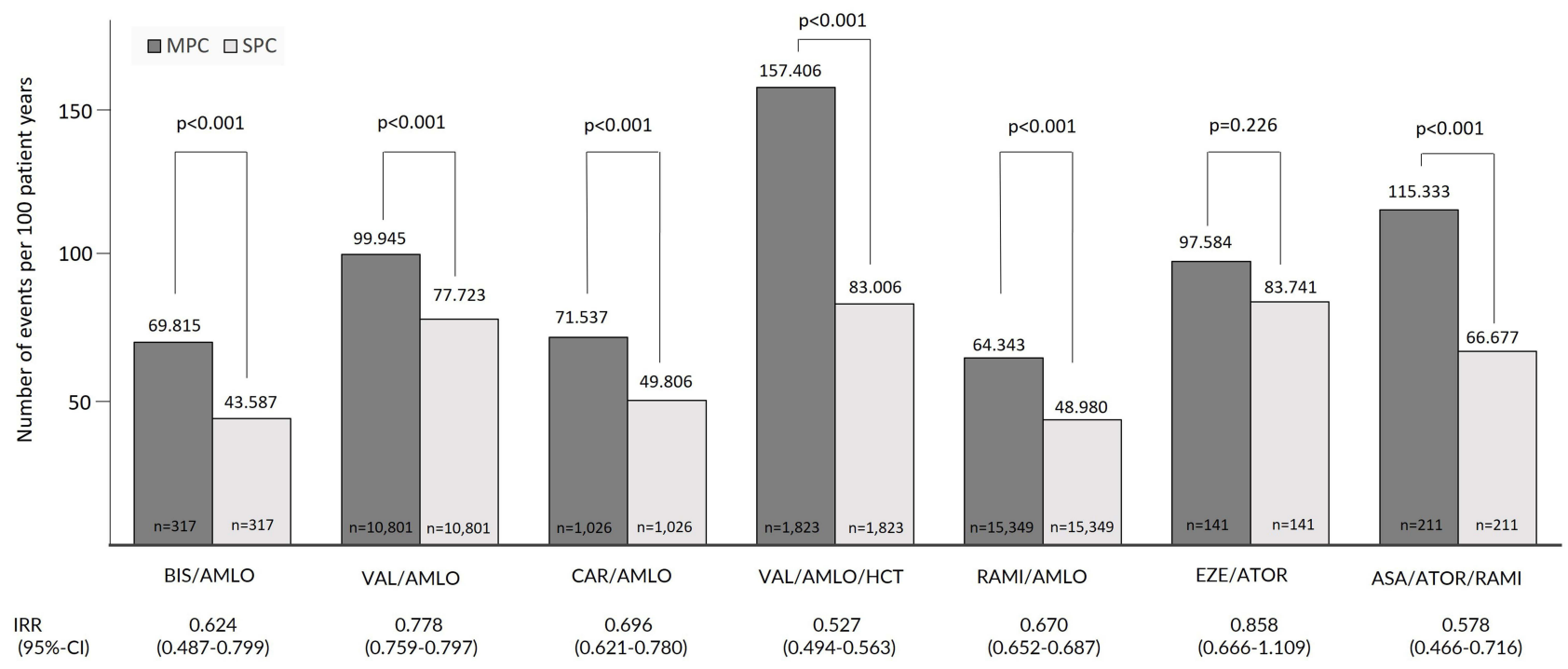

Figure 3 The number of all-cause hospitalizations per observed 100 patient years in the respective cohorts. Comparisons are done between matched SPC versus MPC cohorts.
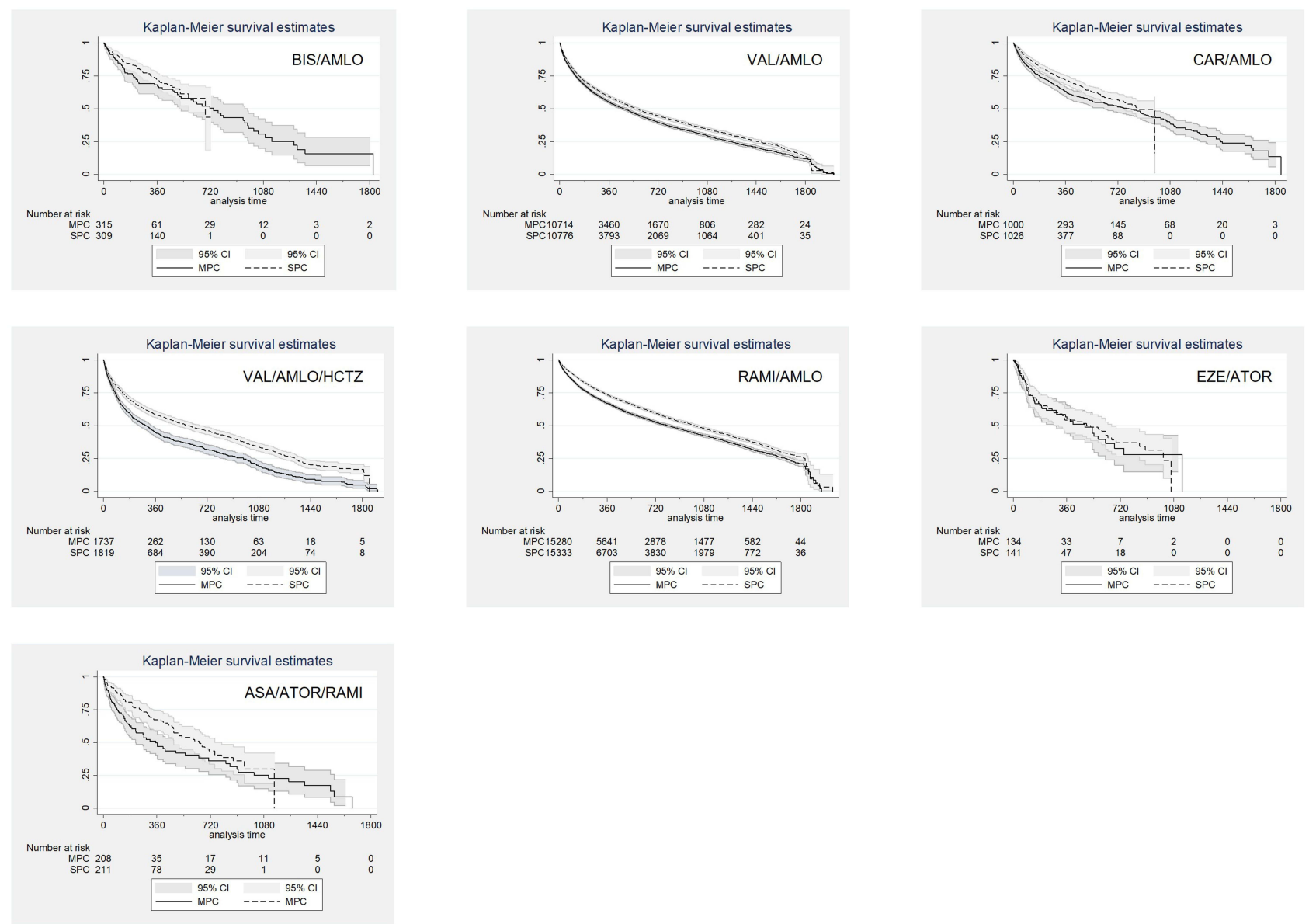

Figure 4 KM curves for the time to the first event regarding the pre-defined composite outcome of all-cause death and all-cause hospitalizations based on a comparison of propensity-score matched SPC versus MPC cohorts. Statistical differences are expressed in terms of Log Rank tests. Censoring was done in case of the following events: switch from SPC to MPC or vice versa, therapy discontinuation defined as gap in drug supply of at least 60 days, end of data availability ( $3 \mathrm{I} / \mathrm{I} 2 / 20 \mathrm{I} 7$ ). 
treatment regimen might not reflect the real-life situation. ${ }^{2}$ Under conditions of daily practice, adherence decreases with any additional pill a patient has to take, even in indications with a lack of physical cues for the patient. ${ }^{3,19}$ Thus, SPC are recommended to improve adherence ${ }^{13,14}$ and blood pressure or lipid control. ${ }^{15}$ Weisser et al could show in a metaanalysis that in hypertension and/or dyslipidemia a SPC leads to better persistence and adherence, an improvement in systolic blood pressure reduction, less outpatient visits, reduced emergency room visits and hospitalizations when compared with the identical MPC. ${ }^{20}$ Our data show for the first time, that a SPC regimen not only leads to a reduction of $\mathrm{CV}$ events and all-cause hospitalizations but also to a reduction of mortality. This is in line with a previous study conducted in the US which analyzed the impact of the type of antihypertensive combination therapy (single-pill triple combination, fixed-dose dual combination plus a third agent, and free triple combination) on the risk of CV hospitalizations. The study demonstrated both for the fixed-dose dual combination plus a third agent group (HR: 3.82) and the free triple combination therapy (HR 3.65) a significantly higher CV event risk than for the single-pill triple combination. ${ }^{21}$

We minimized confounding on patients' data by using PSM in the population analyzed. By comparing identical drug combinations, we also excluded an influence of different compounds on the clinical outcomes by the expectation, that all drugs prescribed were properly taken by the patient. So, the only relevant difference between the treatment groups was the route of administration either as SPC or as MPC.

We found that that SPC increase persistence to medication, and reduce frequency of CV events, hospitalizations and mortality which strongly supports the SPC as a concept. However, this concept does not yet seem to be implemented in daily practice. This is reflected by another finding of our study: despite the recommendations of clinical guidelines to prefer SPC, from 195,348 patients that received one of the predefined combinations 142,726 received MPC and 52,622 SPC only before PSM in the population we analyzed. Looking on the demographic data before PSM, patients who received a SPC regimen were, with the exception of EZE/ATOR, younger and less comorbid than patients receiving an MPC regimen. With the exception of patients on VAL/AMLO/HCTZ and EZE/ATOR, the number of identified MPC patients was higher than the SPC patients, and among RAAS-blocker/amlodipine combinations which represent the majority of patients, number of identified MPC patients was up to seven times higher (CAR/AMLO) than that of SPC patients. However, these data do not allow to identify a clear rationale for the preference of prescribing physicians for a SPC or MPC regimen but reflect an undertreatment of patients with SPC. This might be related to physician's habit to take one of the combination agents, and then "easily" add the second or third agent. Lázaro and colleagues conducted a national, multicenter, observational study of data obtained from physicians by questionnaire and from the clinical records of patients with ischemic heart disease. Main variable was therapeutic inertia during a consultation, defined as treatment remaining the same despite a change being indicated. They found that $43 \%$ of consultations involved therapeutic inertia. In addition, they observed that an association with coronary risk factors, including diabetes, did not result in a change in treatment. ${ }^{22}$

Due to the observational design this study has limitations. To address this, we compared PSM cohorts. We qualitychecked our PSM by comparing hip and knee replacement surgery frequencies as an outcome potentially independent of exposure to SPC or MPC regimens. We could not detect any major differences in number of hip/knee replacement surgeries. Nevertheless, we cannot completely rule out the risk that there were remaining differences between compared patient cohorts, such as percentage of patients receiving primary or secondary CV outcome prevention. Second, we only had access to claims-based proxies to identify the outcomes of interest. To address potential weaknesses of the study resulting from this, we observed multiple outcomes. Third, follow-up periods were significantly different between SPC and MPC regimens mainly due to the higher persistence of SPC patients with their treatment. To minimize the risk resulting from misclassification, we only observed included events requiring an acute hospital admission and a documentation of the event itself as main diagnosis. A potential additional limitation is that due to data limitations, it was not possible to report patients with "pure" hypertension etc., or primary/secondary prevention. However, we followed a drug-centric approach by observing and comparing patients who started to receive the very same drug combination, additionally ensuring that the patients were diagnosed with the diseases which are part of the label of the target drugs. By using PSM based on 29 different variables potentially associated with the CV risk of a patient, we 
ensured that the patients in the SPC and MPC groups are comparable, that includes most probably the percentage of primary/secondary prevention.

Another limitation is that we did not install an adjudication committee of endpoints. However, we used ICD to code diseases and outcomes coded by German claims data, which are a valid and common source of data for analyses of realworld treatment of patients including health-economic analyses. Validity of recording and coding is high in these data, especially for inpatient and prescription data, as they are directly relevant for reimbursement of hospitals/pharmacies, and regularly checked by external agencies. Moreover, study site and patient selection bias are generally absent in these databases as all insured patients meeting the inclusion criteria. Nevertheless, with a $100 \%$ accuracy we could rely on the outcome parameter "all-cause mortality".

In conclusion, our study shows improvement of outcomes with SPC versus MPC regimen including lower CV event risk and a lower mortality. However, CPC are less commonly described than MPC. In line with existing guidelines, increasing efforts are needed to increase the percentage of patients receiving a SPC to optimize outcome reduction.

\section{One - Sentence Summary}

The START study (Effect of SPCs on Treatment Adherence and persistence as well as on clinical and pharmacoeconomic outcomes in the Real-world Treatment of hypertension, CHD, hyperlipidemia and in secondary prevention of CV events START) demonstrated that a SPC is associated with a lower real-world CV event and mortality risk than a MPC.

\section{Data Sharing Statement}

The data that support the findings of this study are abstracted from anonymized claims data sets. Data were available for research purposes from the sickness fund upon request, in an anonymized form. Due to the German data protection law (SGB X) and restrictions around revealing patients' confidential information, data are neither publicly available nor can be shared further.

\section{Acknowledgments}

All authors made a significant contribution to the work reported, whether that is in the conception, study design, execution, acquisition of data, analysis and interpretation, or in all these areas; took part in drafting, revising or critically reviewing the article; gave final approval of the version to be published; have agreed on the journal to which the article has been submitted; and agree to be accountable for all aspects of the work.

\section{Funding}

This analysis was supported by APONTIS PHARMA GmbH \& Co. KG, Monheim, Germany.

\section{Disclosure}

TW is head of IPAM e.V. which did the analyses described in this study. IPAM receives financial support for its studies. OR is employee of APONTIS PHARMA. SM is an employee of Ingress-health HWM GmbH which developed the study protocol; that work was financially supported by Apontis. UM is employee of AOK PLUS. BW reports honoraria for CME from Apontis Germany GmbH, outside the submitted work. SW reports consultancy fees from Apontis Pharma, outside the submitted work. MB reports personal fees from Abbott, Amgen, Astra Zeneca, Bayer, Boehringer Ingelheim, Bristol Myers Squibb, Cytokinetics, Medtronic, Novartis, Servier, and Novartis, outside the submitted work. The authors report no other conflicts of interest in this work.

\section{References}

1. Wilkins E, Wilson L, Wickramasinghe K, et al. European cardiovascular disease statistics 2017: European Heart Network; 2017.

2. Cesari M, Pessina AC. Combined antihypertensive and lipid-lowering treatment. Curr Hypertens Rep. 2004;6(4):300-306. doi:10.1007/s11906-0040025-5

3. Williams B, Mancia G, Spiering W, et al. 2018 ESC/ESH guidelines for the management of arterial hypertension. Eur Heart J. 2018;39 (33):3021-3104. 
4. Gupta P, Patel P, Štrauch B, et al. Risk factors for nonadherence to antihypertensive treatment. Hypertension. 2017;69(6):1113-1120. doi:10.1161/ HYPERTENSIONAHA.116.08729

5. Burke TA, Sturkenboom MC, Lu SE, Wentworth CE, Lin Y, Rhoads GG. Discontinuation of antihypertensive drugs among newly diagnosed hypertensive patients in UK general practice. J Hypertens. 2006;24(6):1193-1200. doi:10.1097/01.hjh.0000226211.95936.f5

6. Corrao G, Zambon A, Parodi A, et al. Discontinuation of and changes in drug therapy for hypertension among newly-treated patients: a population-based study in Italy. J Hypertens. 2008;26(4):819-824. doi:10.1097/HJH.0b013e3282f4edd7

7. Elliott WJ. What factors contribute to the inadequate control of elevated blood pressure? J Clin Hypertens. 2008;10(1 Suppl 1):20-26. doi:10.1111/ j.1524-6175.2007.08028.x

8. Brixner DI, Jackson IKCI, Sheng X, Nelson RE, Keskinaslan A. Assessment of adherence, persistence, and costs among valsartan and hydrochlorothiazide retrospective cohorts in free-and fixed-dose combinations. Curr Med Res Opin. 2008;24(9):2597-2607. doi:10.1185/ 03007990802319364

9. Chowdhury R, Khan H, Heydon E, et al. Adherence to cardiovascular therapy: a meta-analysis of prevalence and clinical consequences. Eur Heart J. 2013;34(38):2940-2948. doi:10.1093/eurheartj/eht295

10. Burnier M. Drug adherence in hypertension. Pharmacol Res. 2017;125(Pt B):142-149. doi:10.1016/j.phrs.2017.08.015

11. Overgaauw N, Alsma J, Brink A, et al. Drug nonadherence is a common but often overlooked cause of hypertensive urgency and emergency at the emergency department. J Hypertens. 2019;37(5):1048-1057. doi:10.1097/HJH.0000000000002005

12. Thornley S, Marshall R, Chan WC, et al. Four out of ten patients are not taking statins regularly during the 12 months after an acute coronary event. Eur J Prev Cardiol. 2012;19(3):349-357. doi:10.1177/1741826711403069

13. Ho PM, Magid DJ, Shetterly SM, et al. Medication nonadherence is associated with a broad range of adverse outcomes in patients with coronary artery disease. Am Heart J. 2008;155(4):772-779. doi:10.1016/j.ahj.2007.12.011

14. Vrijens B, Vincze G, Kristanto P, Urquhart J, Burnier M. Adherence to prescribed antihypertensive drug treatments: longitudinal study of electronically compiled dosing histories. BMJ. 2008;336(7653):1114-1117. doi:10.1136/bmj.39553.670231.25

15. Simons LA, Ortiz M, Calcino G. Persistence with a single pill versus two pills of amlodipine and atorvastatin: the Australian experience. Med J Aust. 2011;195(3):134-137. doi:10.5694/j.1326-5377.2011.tb03240.x

16. Burnier M. Medication adherence and persistence as the cornerstone of effective antihypertensive therapy. Am J Hypertens. 2006;19 (11):1190-1196. doi:10.1016/j.amjhyper.2006.04.006

17. Grimmsmann T, Himmel W. Comparison of therapy persistence for fixed versus free combination antihypertensives: a retrospective cohort study. BMJ Open. 2016;6(11):e011650. doi:10.1136/bmjopen-2016-011650

18. Xie L, Frech-Tamas F, Marrett E, Baser O. A medication adherence and persistence comparison of hypertensive patients treated with single-, double- and triple-pill combination therapy. Curr Med Res Opin. 2014;30(12):2415-2422.

19. Gerbino PP, Shoheiber O. Adherence patterns among patients treated with fixed-dose combination versus separate antihypertensive agents. Am $J$ Health Syst Pharm. 2007;64(12):1279. doi:10.2146/ajhp060434

20. Weisser B, Predel H-G, Gillessen A, et al. Single pill regimen leads to better adherence and clinical outcome in daily practice in patients suffering from hypertension and/or dyslipidemia: results of a meta-analysis. High Blood Press Cardiovasc Prev. 2020;27(2):157-164. doi:10.1007/s40292020-00370-5

21. Wang X, Chen H, Essien EJ, et al. Risk of cardiovascular outcomes and antihypertensive triple combination therapy among elderly patients with hypertension enrolled in a Medicare Advantage Plan (MAP). Am J Cardiovasc Drugs. 2020;20(6):591-602. doi:10.1007/s40256-020-00395-0

22. Lázaro P, Murga N, Aguilar D, Hernández-Presa MA. Therapeutic inertia in the outpatient management of dyslipidemia in patients with ischemic heart disease. The Inertia Study. Rev Esp Cardiol. 2010;63(12):1428-1437. doi:10.1016/S1885-5857(10)70277-2

\section{Publish your work in this journal}

Integrated Blood Pressure Control is an international, peer-reviewed open-access journal focusing on the integrated approach to managing hypertension and risk reduction. Treating the patient and comorbidities together with diet and lifestyle modification and optimizing healthcare resources through a multidisciplinary team approach constitute key features of the journal. This journal is indexed on American Chemical Society's Chemical Abstracts Service (CAS). The manuscript management system is completely online and includes a very quick and fair peer-review system, which is all easy to use. Visit http://www.dovepress.com/testimonials.php to read real quotes from published authors.

Submit your manuscript here: https://www.dovepress.com/integrated-blood-pressure-control-journal 